\title{
Pesquisas científicas envolvendo a ferramenta GeoGebra: estudos promovidos nos cursos de Graduação e Pós-Graduação de Matemática/Faccat
}

\section{Resumo}

As mídias, cada vez mais, fazem parte da rotina de uma sociedade. Os recursos contidos nas tecnologias podem auxiliar os indivíduos a compreender e a perceber o meio em que estão inseridos. Logo, a tecnologia informática é um importante recurso didático para utilização nas escolas. Essa investigação tem por objetivo apresentar as pesquisas científicas utilizadas como meios de aprendizagem dos graduandos e pós-graduandos das Faculdades Integradas de Taquara - Faccat, que ocorreram no ano de 2012, bem como a sua importância no meio educacional atual. A pesquisa classifica-se como qualitativa devido à descrição dos resultados obtidos.

Palavras-chave: Ferramenta informática. Pesquisa. GeoGebra.

\begin{abstract}
The media takes part in a society more and more. The resources, which are hold in technology, can help people to understand and even realize the environment where they are inserted in. Therefore, computer technology in an important didactic resource to be used in schools. This survey aims to present the scientific researches which were used as a learning method by the graduate and postgraduate students of Faculdades Integradas de Taquara - Faccat, that occured in 2012, and its importance in current educational area as well. Research categorizes as qualitative due to description of acquired results.
\end{abstract}

Keywords: Computer data processing tool. Research. GeoGebra.

\footnotetext{
${ }^{1}$ Professora das Faculdades Integradas de Taquara - Faccat - Taquara (RS). Mestre em Ensino de Ciências e Matemática. lucielidescovi@faccat.br
} 


\section{Introdução}

A tecnologia tem avançado muito nos últimos anos. Por isso, as tecnologias de informação e comunicação têm ocupado um espaço cada vez maior na sociedade, o que nos leva a uma verdadeira revolução tecnológica.

Baseadas nos pressupostos citados anteriormente, muitas pesquisas estão sendo realizadas nos cursos de graduação e pós-graduação envolvendo as Tecnologias de Informação e Comunicação, doravante chamadas TICs, entre algumas dessas, e com grande potencial de exploração, está o GeoGebra. Essa ferramenta pode contribuir e realizar um papel de importância nas aulas de Matemática. Sendo assim, esta pesquisa buscar ressaltar o valor da inserção das novas tecnologias no campo educacional e a utilização do software GeoGebra como uma ferramenta auxiliar no ensino da Matemática.

O presente trabalho aborda algumas pesquisas científicas realizadas envolvendo a ferramenta informática GeoGebra, bem como abordagens teóricas e experimentais abarcando a utilização desse recurso durante algumas aulas.

A pesquisa classifica-se como qualitativa quanto à forma de abordagem do problema. Para Ludke e André (1986), os dados coletados em uma pesquisa qualitativa devem ser predominantemente descritivos, devendo o pesquisador estar atento ao maior número possível de elementos estudados. Tem-se como objetivo apresentar alguns estudos desenvolvidos no ano 2012 no curso de Graduação de Matemática e Pós-Graduação em Educação Matemática e Novas tecnologias das Faculdades Integradas de Taquara. Trata-se de um estudo de cunho bibliográfico.

\section{Educação Matemática e as novas tecnologias}

Não apenas o uso da tecnologia é importante, mas a ferramenta adequada a ser utilizada também. Utilizar os recursos sem ter um objetivo claro pode confundir e até mesmo desestimular o aprendizado. No ensino da Matemática, como requer uma associação prática do indivíduo, é muito comum utilizar simuladores e softwares educacionais.

A partir do estado inicial do aluno, dos conhecimentos prévios de que esse dispõe, o professor organiza e planeja o novo conteúdo a ser desenvolvido de tal forma que repercuta diretamente no processo de ensino e de aprendizagem. A esse respeito, uma afirmação mais contundente é a relação dos conhecimentos prévios do aluno com os processos educativos. Ao iniciar esse processo, não é necessário saber tudo o que o aluno sabe, mas sim o que é necessário para saber como organizar e planificar ${ }^{2}$ as aulas de maneira compreensiva aos alunos. Sabe-se que há pessoas que podem ser mais ou menos ricas em conhecimentos, de acordo com suas experiências e informações a que tiveram acesso.

${ }^{2}$ Planificar está relacionado ao planejamento escrito do professor para o desenvolvimento da aula. 
Considerando todos os aspectos, conforme Miras (2001, p. 56):

Para ensinar de modo coerente com o estado inicial dos alunos, temos de tentar averiguar a disposição, os recursos e as capacidades gerais, assim como seus conhecimentos prévios. Essas são as cartas com as quais iniciamos cada rodada da partida.

Segundo os Parâmetros Curriculares Nacionais - PCNs (BRASIL,1997), em busca de novas oportunidades em prol da melhoria da qualidade do ensino, novos desafios relacionados ao ensino são propostos em nossas escolas. No entanto, com o uso da tecnologia de informação, é possível repensar a nossa prática docente, proporcionando novos modelos que nos levem a uma melhor compreensão do objeto em estudo e do perfil do nosso aluno.

As mídias, cada vez mais, fazem parte da rotina de uma sociedade. Os recursos contidos nas tecnologias podem auxiliar os indivíduos a compreenderem e a perceberem o meio em que estão inseridos.

Segundo Valente (2002), se o computador pode ser usado para catalisar e auxiliar a transformação da escola, mesmo diante dos desafios que essa transformação nos apresenta, essa solução, a longo prazo, é mais promissora e mais inteligente do que usar o computador para informatizar o processo de ensino (VALENTE, 2002, p. 21).

Dessa forma, justifica-se a necessidade de maior dinamização da informática na educação e a compreensão do papel que as novas tecnologias poderão desempenhar no contexto educacional. Isso porque, para educar utilizando sistemas informáticos, é necessário que o professor use o computador como ferramenta para o ensino-aprendizagem dos alunos.

Como define Santarosa (2010, p. 123), “[...] consideramos que 'software' educacional é todo o programa que pode ser usado para algum objetivo educacional, seja qual for sua natureza, ou finalidade para qual tenha sido desenvolvido". O planejamento docente é fundamental para que o recurso seja utilizado com objetivo de aprendizagem, a fim de conhecer as potencialidades de exploração do aplicativo, seja qual for seu objetivo.

Existem diversos aplicativos grátis construcionistas ${ }^{3}$ cujas potencialidades podem ser exploradas pelo professor em sala de aula. Tal escolha torna necessário um planejamento prévio, realizado pelo professor, das atividades a serem trabalhadas.

Usar o computador como ferramenta de ensino, segundo Valente (2002), propicia a construção do conhecimento, ou seja, com a finalidade de facilitar essa construção de acordo com a capacidade individual dos alunos, objetivando o ensino e aprendizagem dos indivíduos. Segundo Valente (2002, p. 14 ), "muitas vezes o professor tem muita dificuldade em realizar esse acompanhamento que pode ser feito pelo computador de maneira muito mais detalhada".

Valente, no artigo Por que o computador na educação? (1993), utilizou argumentos para responder a essa questão, sendo um deles o de utilizar o computador como um catalisador de uma mudança no contexto social.

${ }^{3}$ Hendres e Kaiber (2005, p. 26) destacam que os programas se caracterizam em dois paradigmas, algoritmo-instrucionista e o heurístico-construcionista. Construcionista possui a noção de que a ênfase está na aprendizagem ao invés de estar no ensino. 


\section{Formação docente e as novas tecnologias}

Borba e Penteado (2001, p. 11) perguntam: “Qual é o problema para qual o computador é a resposta?". Hoje muitas pessoas se perguntam até que ponto o computador possibilita a aprendizagem para os alunos sem que eles o utilizem como um simples passatempo, mas sim com uma ferramenta potencialmente significativa na aprendizagem de conceitos matemáticos. Para os autores (2001), assim como o papel, o lápis, o quadro e o giz são ferramentas tecnológicas, a calculadora e o computador também são tecnologias utilizadas para aperfeiçoar e visualizar tornando algo mais concreto, mais simples de ser compreendido e até de ser explicado.

Dessa forma, o computador é muito mais que uma ferramenta. Nele há dezenas de possibilidades, usando aplicativos para leitura, para pesquisa de livros, de história da Matemática, para auxiliar na visualização de um gráfico ou de uma figura, sem citar os diversos outros aplicativos existentes na Internet, outra grande ferramenta usada.

Borba e Penteado (2001, p. 54) enfatizam que "[...] alguns professores procuram caminhar numa zona de conforto onde quase tudo é conhecido, previsível e controlável." Alguns docentes não procuram novas maneiras, novas técnicas de aprendizagem, isto é, não estão buscando conhecimentos envolvendo metodologias de abordagem das TICs. Logo, suas práticas estão paradas e alienadas à monotonia e às aulas tradicionais, já que não há busca de novas alternativas de melhoria ao ensino da sua disciplina, limitando também um estudo transdisciplinar em outras áreas de ensino.

É necessário, portanto, levar em consideração os conhecimentos prévios que os alunos possuem, para que, usando suas capacidades intelectuais, cognitivas e sociais, possam atribuir novos significados aos conceitos adquiridos. Esse é um requisito fundamental, o ponto de partida para que o planejamento escolar esteja adequado às exigências atuais.

Nesse sentido, é necessário definir os "conhecimentos prévios". Conforme Pozo et al. (1991), é comum haver uma confusão com relação aos conhecimentos prévios, chegando a significar o conjunto de conteúdos que professores das séries anteriores ensinaram e que os alunos deveriam ter aprendido. $O$ importante é compreender como é o conhecimento que esse sujeito tem em um determinado momento de sua vida em relação a um objeto, sendo fundamental refletir sobre a forma como esse sujeito aprende, ou seja, ao reformular, organizar o conhecimento prévio, a fim de aumentá-lo.

De acordo com os Parâmetros Curriculares Nacionais (BRASIL,1997, p. 47):

Quanto aos 'softwares' educacionais, é fundamental que o professor aprenda a escolhê-los em função dos objetivos que pretende atingir e de sua própria concepção de conhecimento e de aprendizagem, distinguindo os que se prestam mais a um trabalho dirigido para testar conhecimentos dos que procuram levar o aluno a interagir com o programa de forma a construir conhecimento.

Nesse sentido, pode-se dizer que é fundamental a atuação do professor principalmente na hora de escolher softwares que possibilitem a construção do conhecimento por parte do aluno e não somente a reprodução de exercícios de uma forma diferente. 


\section{GeoGebra: ferramenta informática de matemática}

Entre diversos aplicativos, o GeoGebra é um programa que pode ser usado na sala de aula para demonstrar e para aplicar diferentes conteúdos de Matemática. No aplicativo, é possível demonstrar conteúdos que o aluno conheceu e que construiu em sua vida escolar, necessários à resolução dos problemas propostos e, desse modo, resgatados para que possa aplicá-los, diminuindo as chances de esquecê-los. O aluno poderá entender o conteúdo um pouco melhor quanto a sua aplicabilidade e ao método de se chegar a essa aplicação, bem como comprovará que a teoria de diversas formas geométricas está correta.

Markus Hohenwarter foi quem criou esse aplicativo. Ele é livre e pode ser acessado em qualquer computador (GEOGEBRA, 2012).

Em artigo publicado na revista Nova Escola, Vichessi (2011, p. 62) destaca que "[...] independentemente do tipo de exercício proposto, o importante é que a turma compreenda o conceito, seja utilizando o computador, seja desenhando a lápis". Logo, o objetivo de utilizar essa ferramenta está muito além de simplesmente saber manuseá-la e sim de aplicar conteúdos vistos em aula e fazer relações entre determinados conteúdos matemáticos.

Não basta utilizar o aplicativo apenas para conhecimento deste. O objetivo é que o aluno possa demonstrar a aplicação e provar o que viu em aula. Essa aplicação não se limita ao aluno: o professor também deve construir um conhecimento a partir da história, explicando a teoria e oferecendo várias soluções para as possibilidades de aplicação, como o desenho a lápis em uma figura feita de cartolina ou no computador, dentre outros, com a utilização do GeoGebra.

No aplicativo, podem ser demonstradas figuras geométricas e suas propriedades, cálculo de ângulos, estudo das funções e muitos outros conteúdos. Segundo Vichessi (2011), ele não serve apenas para trabalhar com mais agilidade e para buscar diversos caminhos de resolução de problemas, mas também para analisar se o que foi feito está correto.

Portanto, o aluno que está a par do conteúdo poderá utilizar seu conhecimento para manusear a ferramenta e para averiguar a aplicabilidade que está apenas na teoria, demonstrando os conceitos já vistos anteriormente, cuja realização explora conceitos que ainda serão trabalhados.

Com o aplicativo GeoGebra podem ser investigados conceitos que envolvem a álgebra e a geometria, possibilitando sua abordagem desde as séries iniciais ao ensino superior. Percebe-se, no entanto, que o trabalho com esse conteúdo exige um pré-conhecimento, para assim utilizar a ferramenta como instrumento de resolução de problemas, aplicando suas operações e visualizando a utilidade do software, que se trata de um material concreto para o ensino do conhecimento.

A Figura 1 apresenta a página inicial do aplicativo GeoGebra: 


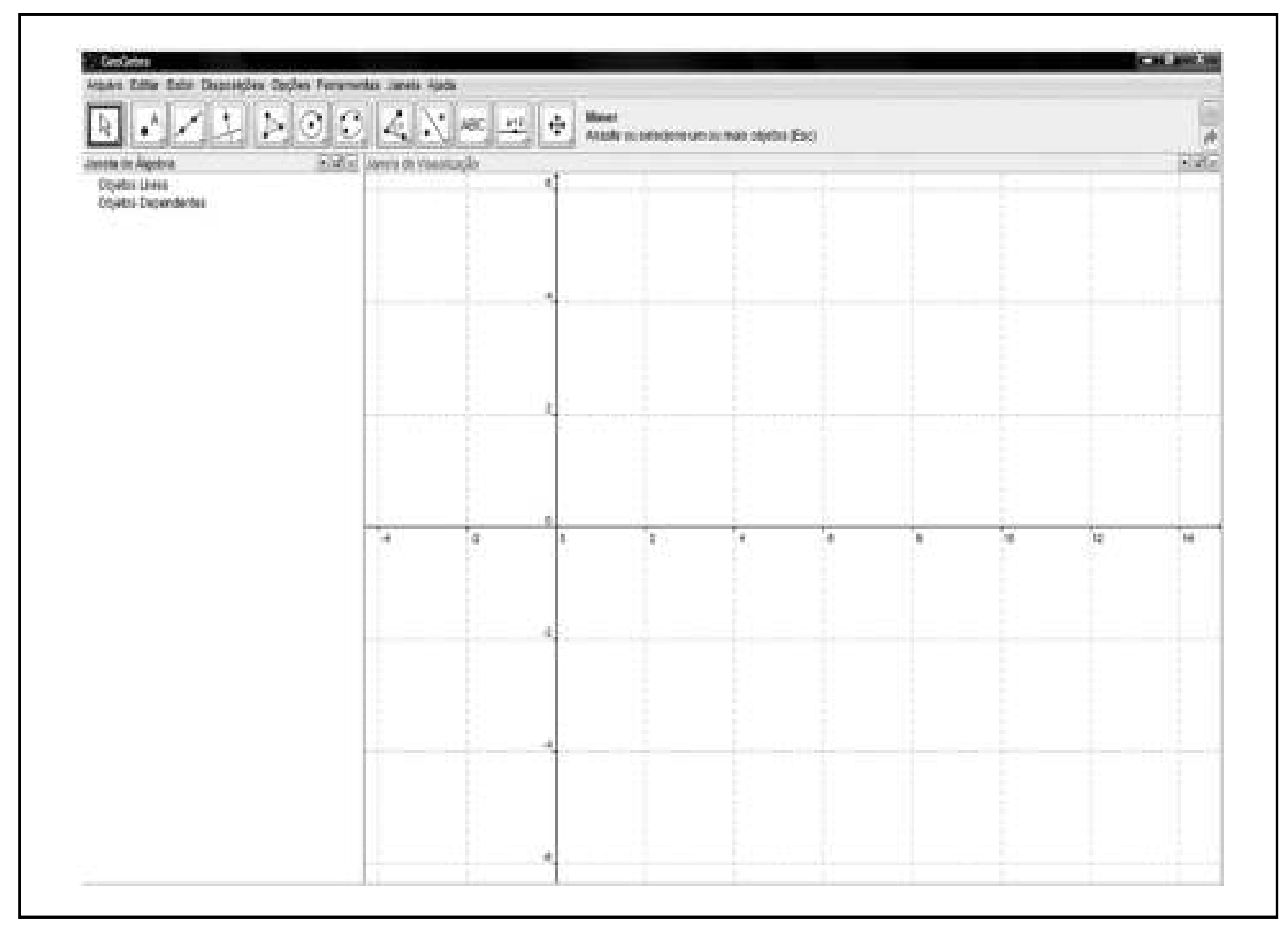

Figura 1: Página inicial do aplicativo GeoGebra Fonte: GeoGebra (2012)

No lado esquerdo superior da tela inicial do GeoGebra (Figura 1), é possível visualizar janelas do domínio da geometria, como ponto, reta e plano, por exemplo.

\section{A pesquisa: experiências desenvolvidas nas Faculdades Integradas de Taquara}

Conforme o colegiado do curso de Matemática, muitas atividades vêm sendo abordadas utilizando a ferramenta GeoGebra durante as disciplinas da graduação e pós-graduação, como em Introdução à Informática, Geometria, entre outras. Além de ser utilizada durante as aulas, essa ferramenta também proporciona pesquisas científicas, por meio de elaboração de artigos e de leituras de livros da área, entre outros.

No ano de 2010, o curso de pós-graduação - em nível de especialização - em Educação Matemática e Novas Tecnologias, participou de um encontro internacional com seis artigos de pesquisa de cunho metodológico, produzidos no curso. Os trabalhos abordavam sequências didáticas envolvendo material concreto e situações-problema e um deles era relacionado à tecnologia. As publicações estão nos Anais do V CIEM (Congresso Internacional de Educação Matemática), que ocorreu na Ulbra no ano de 2010 e que contou com oito apresentações representando o já referido curso de pós-graduação da Faccat.

Os trabalhos de conclusão do curso, disponíveis na biblioteca da instituição, também abordam tal ferramenta. Entre esses trabalhos, podemos citar títulos, como "Explo- 
ração das potencialidades da ferramenta tecnológica GeoGebra no ensino da Matemática" e "O uso do software GeoGebra no ensino da geometria na sétima série do ensino fundamental".

A Mostra Científica do ano de 2012 na Faccat trouxe doze trabalhos envolvendo pesquisas desenvolvidas durante o curso de graduação e pós-graduação do curso de Matemática. Entre eles, destacam-se as investigações desenvolvidas envolvendo o recurso tecnológico GeoGebra. Passamos a elencar essas pesquisas publicadas na Mostra Científica Faccat no ano de 2012.

As autoras Silva e Bischoff (2012), com o título "As Novas Tecnologias e o Ensino da Matemática", apresentaram a pesquisa desenvolvida com alunos no laboratório de informática, em que cada um deveria construir no mínimo três circunferências que tivessem medidas de raios diferentes. Posteriormente, deveriam ir ao ícone perímetro e calcular a medida do perímetro de cada uma das circunferências. A Figura 2 apresenta uma das atividades analisadas pelas pesquisadoras, alunas da Faccat.

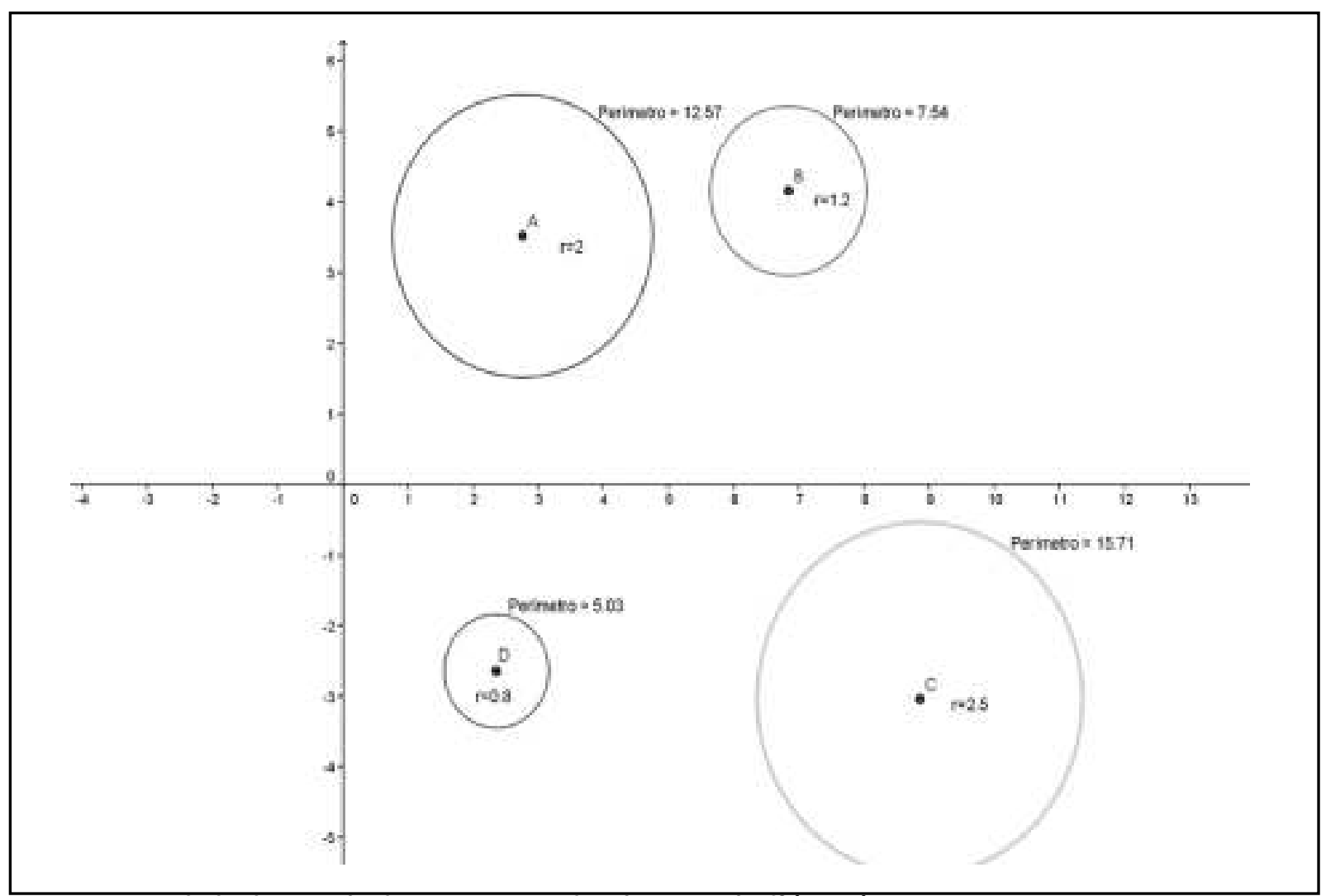

Figura 2: Atividade desenvolvida na pesquisa de Silva e Bischoff (2012)

Fonte: GeoGebra (2012)

Já as autoras Gerft, Pereira e Rosa (2012) destacaram a ferramenta como um recurso exploratório de atividade no plano cartesiano intitulado de "GeoGebra: Um Novo Recurso Tecnológico".

O trabalho permite aos alunos aplicarem conhecimentos de conceitos como números inteiros, simetria, cálculos aritméticos, entre outros.

A Figura 3 apresenta uma imagem, destacada no artigo, de como nomear, colorir, fixar objeto, alterar o traçado, disponíveis no programa GeoGebra. 


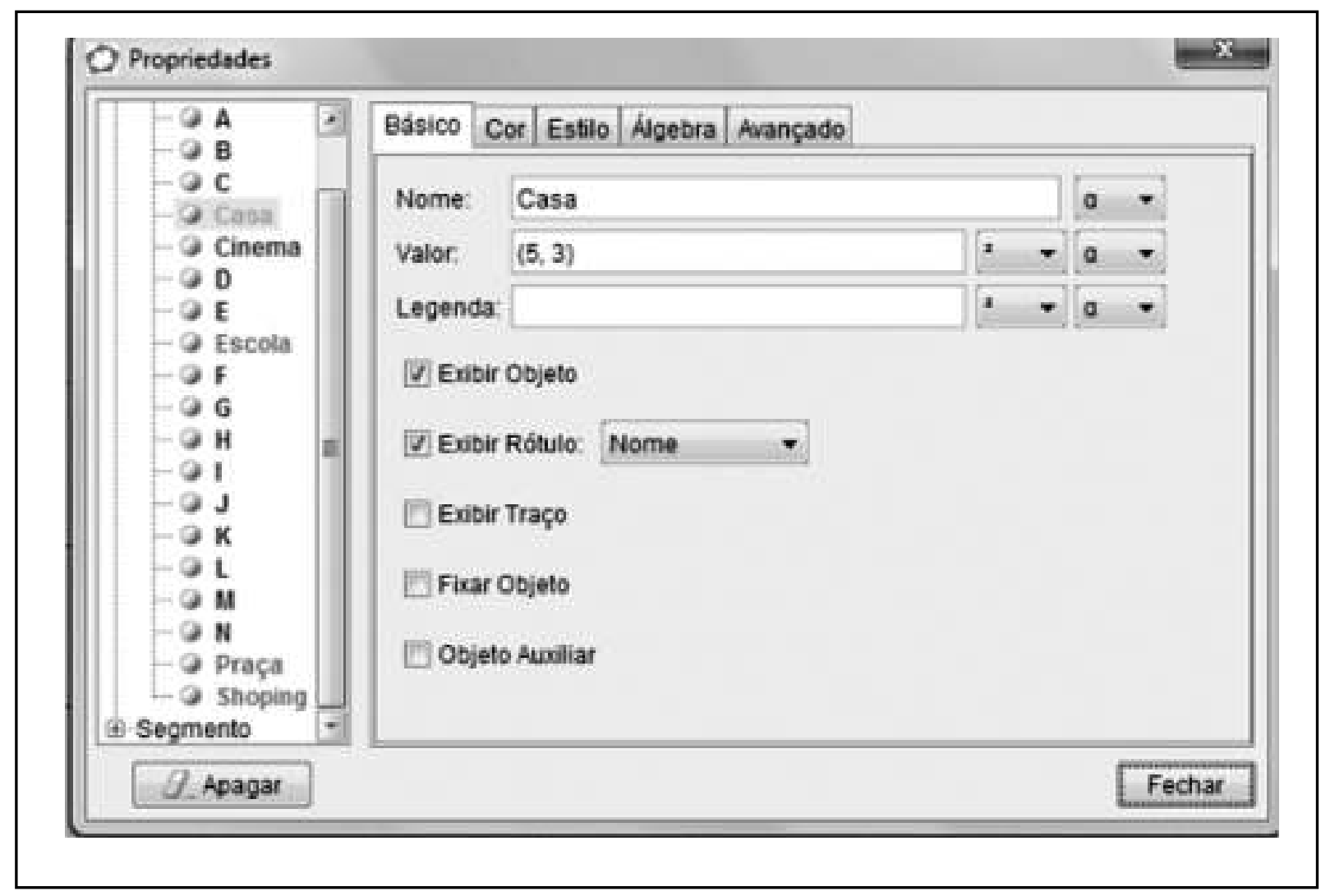

Figura 3: Imagem do artigo Gerft, Pereira e Rosa (2012)

Fonte: GeoGebra (2012)

Na figura 4, é possível destacar o trabalho já desenvolvido a partir da proposta das autoras, delinear um mapa a partir das instruções no GeoGebra clique em exibir $e$, logo em seguida, malha. Possibilita que o plano fique quadriculado. Para inserir os pontos solicitados, selecione o segundo ícone (novo ponto) e marque o caminho para o encontro: (5,3) Casa de Leonardo; (-2,5) Praça; (-3,-5) Shopping; (4,-4) Escola; $(6,-3)$ Cinema. Em seguida, foi então proposto que desenhassem o mapa: Clicar no 3o ícone e selecionar o segmento definido por dois pontos. Siga as seguintes condições: partindo de casa, ande $2 \mathrm{~cm}$ para baixo; ande $7 \mathrm{~cm}$ para a esquerda; suba $5 \mathrm{~cm}$; ande $1 \mathrm{~cm}$ para a para direita; desça $8 \mathrm{~cm}$; ande para direita $7 \mathrm{~cm}$; para baixo, $2 \mathrm{~cm}$; ande para direita $1 \mathrm{~cm}$; para cima, $3 \mathrm{~cm}$; para esquerda, $10 \mathrm{~cm}$; para baixo, $3 \mathrm{~cm}$; para direita, $6 \mathrm{~cm}$; para cima, $1 \mathrm{~cm}$; para direita, $1 \mathrm{~cm}$; baixar $1 \mathrm{~cm}$. 


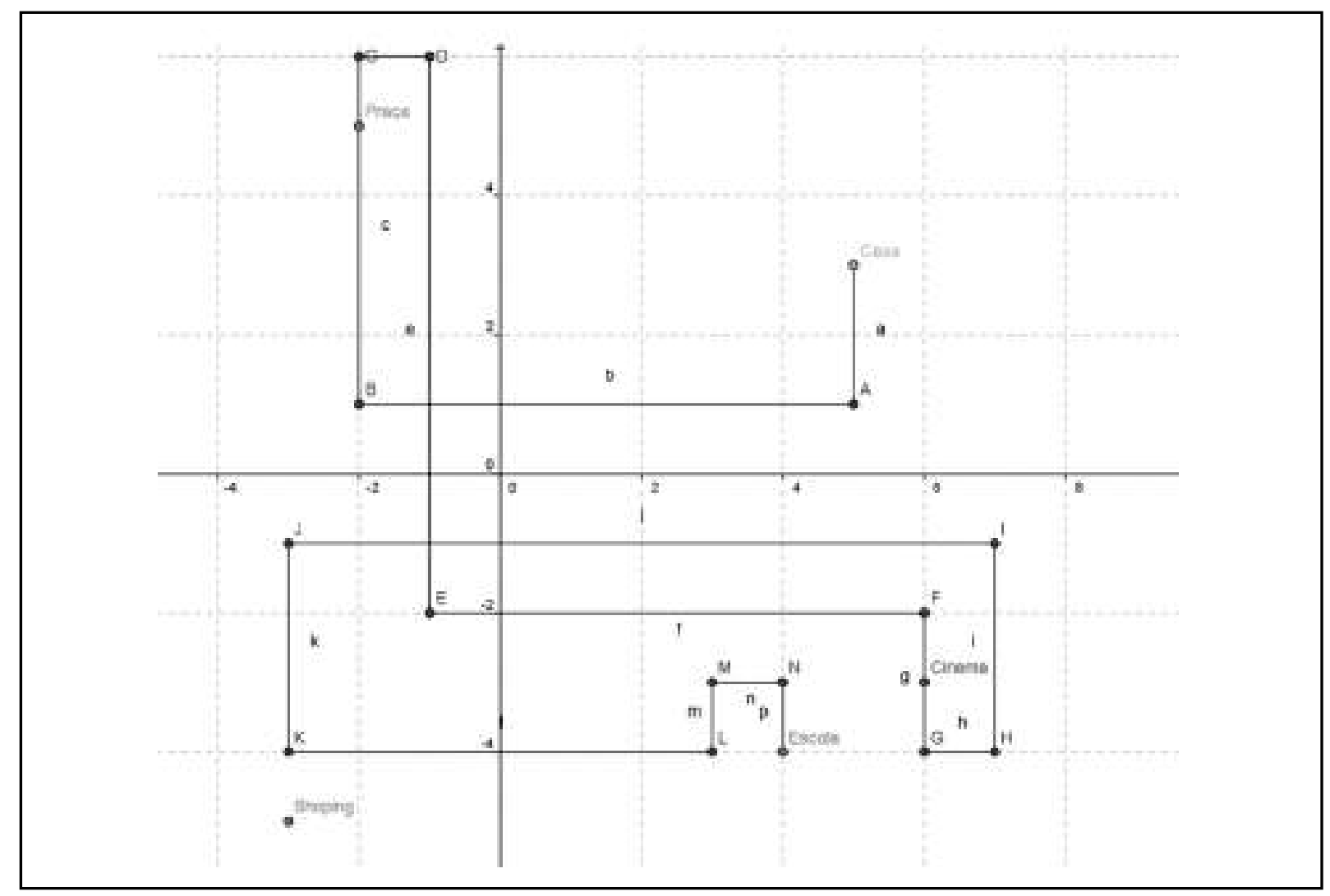

Figura 4: Atividade finalizada no GeoGebra

Fonte: Gerft, Pereira e Rosa (2012)

Da pesquisa "GeoGebra: uma ferramenta que vai ao encontro do ensino da Matemática", das autoras Taube e Silva (2012), destacamos incentivos para pesquisas oferecidas pelo governo, como, por exemplo, EDUCOM, FORMAR, PRONINFE e PROINFO. Além disso, a pesquisa contou com a atividade envolvendo o Tangram ${ }^{3}$ no software GeoGebra: a) Construa as peças do tangram no software GeoGebra e monte o Tangram a partir de um quadriculado com 16 quadrados, cada um com $1 \mathrm{~cm}$ de lado. b) Calcule a área das peças que formam o Tangram e comparem com a área do quadriculado. c) Determine a área de um quadrado formado pelos dois triângulos maiores. d) Construa duas figuras com as peças do Tangram que apresentam a mesma área. e) Calcule o perímetro das duas figuras construídas. f) Verifique se os triângulos que fazem parte do Tangram são semelhantes entre si ou não. Segundo as pesquisadoras (2012), ao realizar as atividades no GeoGebra, possibilita-se que os alunos retomem conceitos de área, perímetro e semelhança entre triângulos e fazerem algumas constatações, já que o GeoGebra é um software que privilegia a visualização, no caso da geometria.

Os autores Zimmer e Belmonte (2012), com o título "O Aplicativo GeoGebra no Estudo de Conceitos Matemáticos", desenvolveram a pesquisa, destacando ainda o papel do professor frente a tais recursos tecnológicos, bem como a formação constante e a importância da pesquisa no planejamento docente. A pesquisa contou com uma atividade envolvendo o software GeoGebra abarcando a construção de polígonos. $O$ problema da investigação foi que o aluno construísse os polígonos estudados, indicando os ângulos internos de cada figura plana construída. Um dos objetivos da atividade era

\footnotetext{
${ }^{3}$ Tangram é um quebra-cabeça chinês formado por sete peças sendo elas: 5 triângulos, 1 quadrado e 1 paralelogramo.
} 
levar o aluno a se apropriar de conceitos relacionados à soma dos ângulos internos de quadriláteros e triângulos. A atividade realizada pode ser observada na Figura 5:

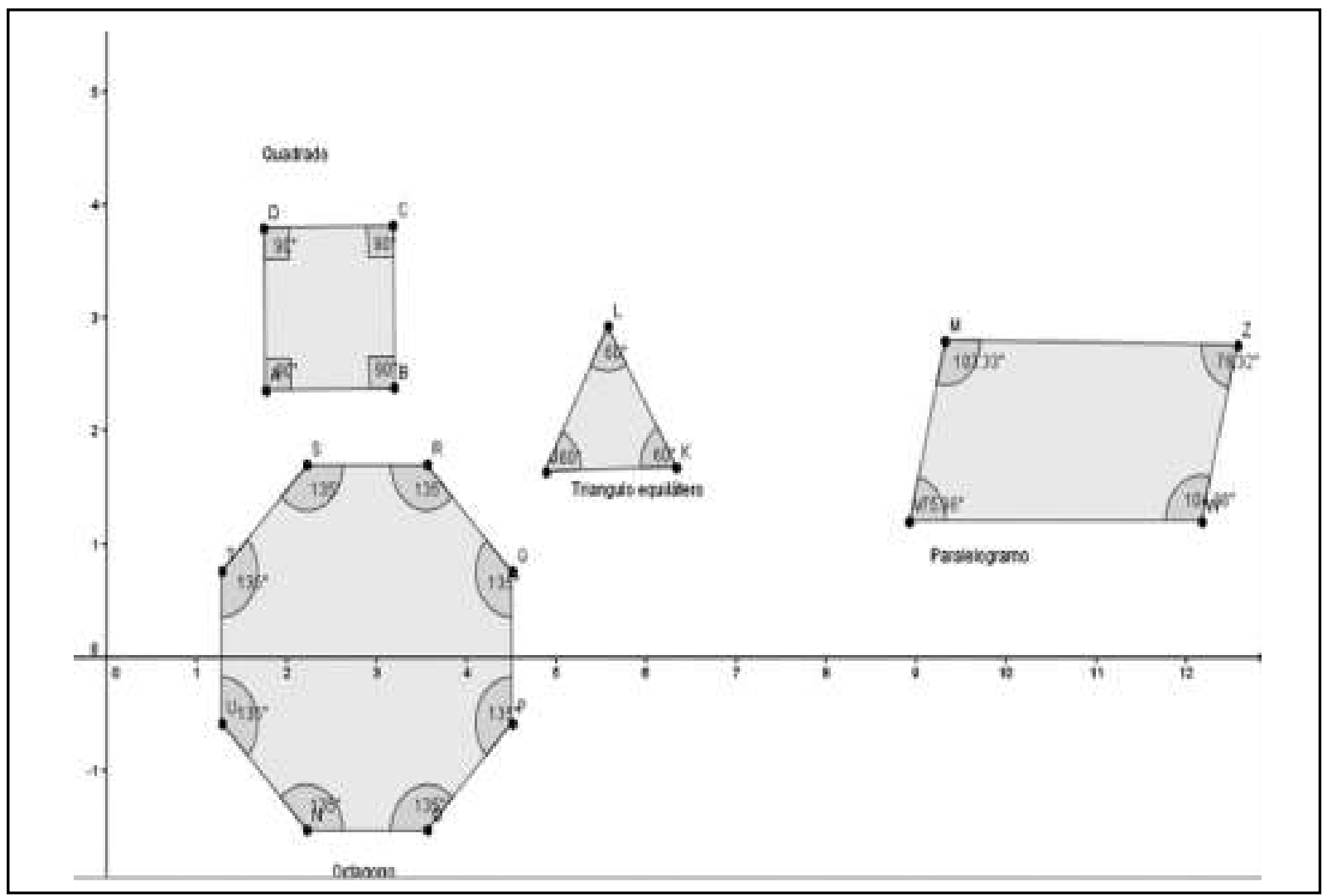

Figura 5: Construção de polígonos do GeoGebra Fonte: Zimmer e Belmonte (2012)

Os autores Zimmer e Belmonte (2012) também destacam a possibilidade de estudar os coeficientes de funções traçados a partir da função quadrática $f(x)=a x^{2}$, com os seguintes valores para seu coeficiente angular. Os valores foram $a=1 / 10, a=1 / 2, a=1, a=2$, $a=5, a=-5, a=-2, a=-1, a=-1 / 2$ e $a=-1 / 10$.

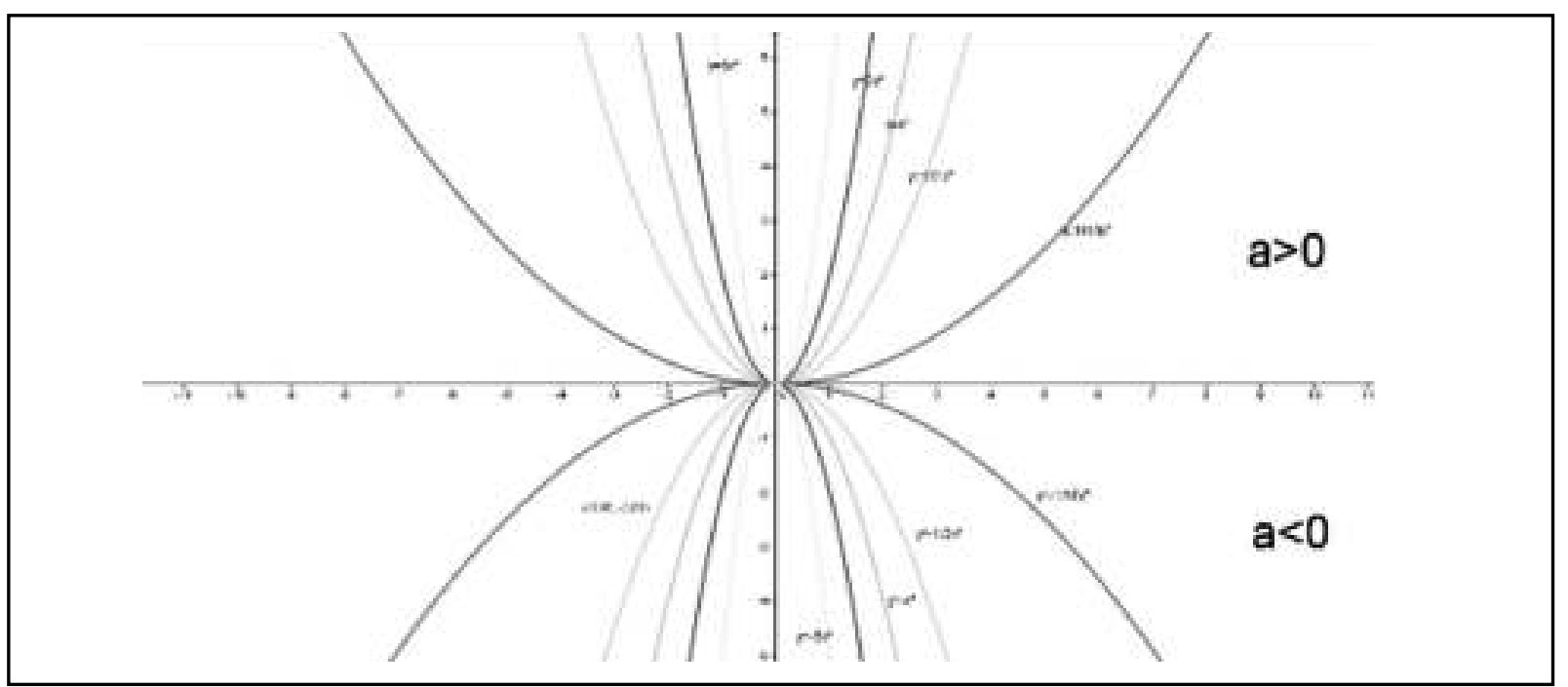

Figura 6: Estudo das funções

Fonte: Zimmer e Belmonte (2012)

94 | COLÓQUIO - Revista Científica da Faccat - v. 9, n. 2, jul./dez. 2012 
Todas as pesquisas foram produzidas com orientação de docentes da Faccat, promovendo o gosto de pesquisar e ainda de apresentar aos interessados experiências cujo como objetivo fundamental é o conhecimento científico de diferentes áreas.

Conforme Vichessi (2011), no aplicativo, podem-se demonstrar figuras geométricas e suas propriedades, cálculo de ângulos, estudo das funções e muitos outros conteúdos. Ele não serve apenas para trabalhar com mais agilidade e para buscar diversos caminhos de resolução de problemas, mas também para analisar se o que foi feito está correto.

\section{Conclusão}

Atualmente, a tecnologia permite desenvolver conceitos por meio da interação entre conhecimento científico e ferramenta informática. A pesquisa científica e a produção de conhecimento estão fundadas no olhar de quem busca alternativas para melhorar e/ou aperfeiçoar práticas pedagógicas ou pessoais.

Todos os estudos destacam que, com o aplicativo GeoGebra, podem ser investigados conceitos que envolvem a álgebra e a geometria, possibilitando sua abordagem desde as séries iniciais até o ensino superior.

Também destacam que o trabalho com o software exige um pré-conhecimento, para assim utilizar a ferramenta como instrumento de resolução de problemas, aplicando suas operações, visualizando e manipulando as ferramentas disponíveis do software, que se trata de um material concreto para o ensino do conhecimento.

Portanto, para ser professor, visto como profissional que necessariamente precisa desenvolver determinadas competências, é indispensável que ocorra uma formação específica e que lhe forneça subsídios teórico-práticos para desempenhar a sua função com competência técnica e política. Não é suficiente que o professor tenha um grande domínio de seu conteúdo específico: é necessário também que esse conteúdo esteja relacionado com o momento vivido pelos homens, que conheça bem a sociedade contemporânea, que detecte e mostre aos seus acadêmicos as contradições presentes em nossas vidas, que mostre porque os homens estão produzindo, hoje, esse modo de vida competitivo, com ênfase na eficiência, em competências múltiplas.

\section{Referências}

BORBA, Marcelo de Carvalho; PENTEADO, Miriam Godoy. Informática e Educação Matemática. Belo Horizonte: Autêntica, 2001.

BRASIL. Secretaria de Educação Fundamental. Parâmetros Curriculares Nacionais: Matemática/Secretaria de Educação Fundamental. Brasília: MEC/SEF, 1997.

GERFT, Cristine; PEREIRA, Debora; ROSA; Maria Regina da. GeoGebra: um novo recurso tecnológico. In: II Salão de Extensão, Pesquisa e Pós-Graduação e X Mostra da Iniciação Cientifica. Anais. Taquara: Faccat, 2012.

GEOGEBRA. Disponível em: <www.GeoGebra.org/cms/pt_BR>. Acesso em: 12 abr. 2012. 
HENDRES, C. A.; KAIBER, C. T. A utilização da informática como recurso didático nas aulas de Matemática. Acta Scientiae Revista de Ciências Naturais, Canoas, v. 7, n. 1, jan./jul. 2005.

LUDKE, M; ANDRÉ, M. Pesquisa em Educação: abordagens qualitativas. São Paulo: EPU, 1986.

MIRAS, M. Um Punto de Partida para el Aprendizaje de nuevos contenidos: Ios conocimentos Prévios. In: COE, C. et al. Constructivismo em el aula, Barcelona: Grao, 2001. p. 47-63.

POZO, J. I et al. Processos cognitivos en la Comprensión de la Ciencia: las ideas de los adolescentes sobre la química. Madrid: Ministerio de Educación y Ciencia, CIDE-MEC, 1991.

SANTAROSA, Lucila Maria Costi (Org.) Tecnologias Digitais Acessíveis. Porto Alegre: JSM Comunicação, 2010.

SILVA, Gioconda; BISCHOFF, Tamara. As novas tecnologias e o ensino de Matemática. In: II Salão de Extensão, Pesquisa e Pós-Graduação e X Mostra da Iniciação Cientifica.

Anais. Taquara: Faccat, 2012.

TAUBE, Clarice; SILVA, Leide Laura. GeoGebra: uma ferramenta que vai ao encontro do ensino de Matemática. In: II Salão de Extensão, Pesquisa e Pós-Graduação e X Mostra da Iniciação Cientifica. Anais. Taquara: Faccat, 2012.

VALENTE, J. A. Por que o Computador na Educação. In: VALENTE, J. A. (Org.).

Computadores e Conhecimento: repensando a educação. Campinas: Unicampi, 1993. p. 24-44.

O Uso Inteligente do Computador na Educação. Pátio, Porto Alegre: Artes Médicas Sul, ano 1, n. 1, p. 19-21, 2002.

VICHESSI, Beatriz. Sete respostas sobre o software GeoGebra. Nova Escola, São Paulo, n. 244, 2011, p. 61- 63.

ZIMMER, Fabio; BELMONTE, Rita. O Aplicativo GeoGebra no Estudo de Conceitos Matemáticos. In: II Salão de Extensão, Pesquisa e Pós-Graduação e X Mostra da Iniciação Cientifica. Anais. Taquara: Faccat, 2012. 